UDC 622.244.442

DOI: 10.15587/2706-5448.2021.229652

Article type «Reports on Research Projects»

\section{Viktoriia Dmytrenko, Yuliia Diachenko}

\title{
THE IMPACT ASSESSMENT OF PLANT OILS ON UNCTUOUSITY OF DRILLING FLUIDS
}

The object of study is natural natural oils.

Lubricating additives based on natural substances - vegetable oils and animal fats - meet the increased requirements for environmental safety of materials used in the drilling process. Consumption of environmentally friendly lubricants is constantly growing and requires an expansion of the raw material base for their production. Therefore today lubricants are important drilling reagents. From the ecological point of view, lubricating additives based on vegetable oils are of the greatest interest.

The main physicochemical properties of sunflower and castor vegetable oils and the influence of these lubricating additives on lubricating and rheological characteristics of drilling fluids were investigated. In addition, the main properties of water-clay drilling fluids were investigated and their main parameters were determined according to standard API methods.

During the testing of the samples, we took into account, first of all, the a shear rate of the filter cake (CPC). It is the value that characterizes the strength of filter cake and is determined by the ratio of strength necessary for the tangential displacement of cyclic load across the cake to its weight. It is the CPC that characterizes the lubricating properties of the samples of solutions with a lubricant additive of a certain concentration that were studied. It is the CPC that characterizes the lubricating properties of the samples of solutions with a lubricant additive of a certain concentration that were studied.

Based on the above studies, it can be concluded that the addition of castor oil effectively reduces the coefficient of friction of the filtration crust formed from the studied drilling fluids (fresh, mineralized, and saline). The recommended concentrations of this oil to the drilling fluid are $0.5 \%, 1 \%$, and $5 \%$. Sunflower oil has an effective effect on the saline solution, less effectively - on the mineralized with an oil concentration of $0.5 \%, 3 \%$, and $5 \%$.

On the basis of the conducted researches the prospects of use of sunflower and castor oils at development of a new compounding of a greasing additive to a drilling mud are defined. Further research is aimed at assessing their lubricity in the drilling fluid at the friction limit «metal-metal». It is planned to repeat the study at the Sticking Tester OFI (USA).

Keywords: well drilling, water-based drilling fluids, coefficient of friction of the crust, filtration of drilling fluids, lubricating properties.

\section{Introduction}

Over the past decade, the situation with gas and oil production has radically changed. Large deposits are mostly depleted, and new structures are mainly represented by deposits of low-flow, low-permeability reservoirs. In many cases, the extraction of hydrocarbons without the use of new technologies becomes very problematic. The most promising, in this case, are technologies based on horizontal drilling.

Any drilling fluid system is not ideal for highly deviated and horizontal wells, but in all cases, it is clear that the drilling fluid should provide effective cuttings removal, high lubricating properties, the stability of the wellbore walls, especially composed of mud cake forma- tions, and the maximum possible preservation of reservoir permeability. At the same time, the solution should be, if possible, easily modified, technological in control, and economically available. Thus, the improvement and development of new drilling fluids that would fully meet the stringent requirements of horizontal drilling are one of the urgent tasks of today.

In recent years, lubricating additives to drilling fluids from the category of special-purpose auxiliary substances, as they were previously classified, are confidently becoming the main reagents.

To date, a significant amount of lubricating additives for drilling fluids has been proposed. They are represented by a wide range of different classes of chemical compounds - 
metal salts (mainly alkaline), fatty acids, fatty acid esters, chlorinated, sulfated, condensed fatty acids, as well as complex mixtures of natural substances.

The most used and most effective additives of Ukrainian production are liquid, pasty, and powder lubricating additives based on products of processing of beef fat SPRiNT-33, mixes of vegetable oils (corn, soybean, sunflower) - FK-2000 and their modifications (FK-2000 Plus, FK-2000 PlusM, FK-2000 plus), Lubri-M, environmentally friendly lubricating additives of the DSB series, traditional lubricating additive ZMAD [1].

Today, lubricating additives are produced and supplied in a wide range by leading foreign chemical companies (CESCO, AVA, Venture, Ibex, Alpine) and drilling service companies (Baroid, M-1 Drilling Fluids, Baker, Messina). There is a tendency to reduce the total number of lubricants [1].

At this point is a list of some of the tested lubricants.

Traditional lubricants are oil, graphite, and SMAD [2].

During the last ten years on the market of lubricants for drilling fluids and process fluids, in addition to traditional chemical reagents - oil and graphite, lubricating impurities based on the modification of waste oil and fat industry (cophos, hydrofuse): labricol, SMD, SMG, Burol and others in Ukraine and FK-2000 in Russia are widespread [3].

However, a new generation of lubricating impurities, such as oil-soluble nonionic surfactants dissolved in hydrocarbons, is beginning to be widely used. Monoethanolamides of synthetic fatty acids, dissolved in motor oils, lubricating compositions for water-based drilling fluids, lubricating impurities, such as Lubry-M, DSB-4TTP, SONBUR-1103, are widely used as lubricating impurities [4].

Bit Lube Export is a product of M-I Drilling Fluids (USA). The main advantages of this additive: it is highly effective in fresh clay drilling fluids and significantly improves their anti-wear, anti-stick properties. Disadvantages: high cost (many times higher than Ukrainian lubricants of the same level); significant transport costs; impossibility of application in systems with highly mineralized dispersion media; insufficiently low pour point (above $-12{ }^{\circ} \mathrm{C}$ ) [5].

TORQ-TRIM is a product of Halliburton (USA). Its main advantages: gives additional lubricating property to solutions under pressure; works in solutions based on fresh and saltwater at different $\mathrm{pH}$ values; is not removed from solution at high concentrations of calcium and magnesium; easily biodegradable; does not form foam in drilling fluid; stable at temperatures above $205{ }^{\circ} \mathrm{C}$. Disadvantages: too high price and significant transport costs [5].

CBR (Ukraine) is made on the basis of products of vegetable origin with the addition of tall oil. The ammonium form of products of saponified fatty acids is characterized by a low degree of ionization, which contributes to their resistance to leaching and aggressive action of polyvalent metal ions. Urea, as one of the ingredients of this reagent, causes its effective homogenization, the selectivity of adhesion, and also helps to inhibit the hydration of minerals. Its main advantages: rapid adsorption on the metal surface (due to amino compounds); salt resistance; heat resistance (due to the ammonium form); improving the impact on the technological parameters of washing fluids; reduction of the coefficient of friction of the crust [5].

DZ-10 - a homogeneous liquid of dark (black) color based on waste hydrocarbons [5].

Graphite GSB-1 (Ukraine) - a lubricating powder - is aimed to improve the lubricating properties of drilling fluid to reduce the likelihood of seizures during drilling. Its main advantages: salt resistance; heat resistance; preservation of properties at low temperatures. Disadvantages: high probability of screening on vibrating screens; compared to individual lubricants, it does not have a multifunctional effect on the improvement of the main indicators of the solution [6].

Labricol (Ukraine) is made based on of products of a vegetable origin with the addition of sulfate soap. Its main advantages: rapid adsorption on the metal surface; salt resistance; heat resistance; improving the impact on the technological parameters of washing fluids, reducing the coefficient of friction of the crust [5].

The suggested compositions of lubricating additives are characterized by multifunctional action, so when choosing them, taking into account the effectiveness in specific geological and technical conditions, it is necessary to allocate special requirements for their quality.

In this work, the object of research is natural oils.

The aim of research is to study the effect of lubricating additives of crude sunflower and castor oils on lubricating and rheological characteristics of fresh, mineralized and salty water-clay drilling fluids in order to improve their lubricating properties.

\section{Methods of research}

Three types of aqueous-clay drilling fluids are used for research, which is widely used during drilling of wells fresh, mineralized, and salt-saturated solutions with a volume of $800 \mathrm{ml}$ each:

- the first type - WBM (water-based mud) - water $+5 \%$ clay (bentonite clay powder);

- the second type - WBM+10\% $\mathrm{KCl}+1 \% \mathrm{CMC}$;

- the third type - WBM+10\% $\mathrm{KCl}+15 \% \mathrm{NaCl}+$ $+1 \%$ CMC.

The work investigated the effect of lubricating additives of syrupy sunflower and castor oils on the physicochemical, lubricating, and rheological characteristics of drilling fluids.

The experiment was carried out using API standard techniques for testing water-based drilling fluids. To characterize the properties of drilling fluids, the following were used: density $\left(\rho, \mathrm{kg} / \mathrm{m}^{3}\right)$, conditional viscosity $(V, \mathrm{~s})$, static shear stresses, filtration, or fluid loss $\left(F, \mathrm{~cm}^{3} / 30 \mathrm{~min}\right)$, filter cake thickness $(K, \mathrm{~mm})$. The crust friction coefficient $(C F C$, $\tan \alpha)$ was measured on a KTK-3 device (USA). The rheological properties of the solutions were determined with a Fann rotational viscometer (USA). The results of measurements were used to calculate the gel strength $\left(\mathrm{Gel10} / 10, \mathrm{ft}^{2}\right)$, plastic viscosity $(P V, \mathrm{cP})$, ultimate dynamic shear stress $\left(Y P, \mathrm{ft}^{2}\right)$, and imaginary viscosity $(A V, \mathrm{cP})$.

At the beginning of the measurements, the parameters of the pure solution were measured. The composition of the solutions used, the results of the experiment are given in Table 1.

After measuring the parameters of the pure solution, the samples were placed for stirring in a paddle stirrer for 30 minutes. Then to each sample slowly, with stirring, was introduced $0.5 \%$ crude sunflower oil, stirred for 25 minutes after the end of the introduction at a high speed $1500 \mathrm{rpm}$. The previous one determined the physicochemical properties of crude sunflower oil. The obtained data are shown in Table 2.

After measuring the parameters of the samples with $0.5 \%$ crude sunflower oil, the samples were placed for 
stirring in a paddle stirrer for 30 minutes. Then to each sample slowly, with stirring, was introduced $1 \%$ crude sunflower oil, stirred for 25 minutes after the end of the introduction at high speed $1500 \mathrm{rpm}$.

Next evaluating the parameters of the samples with $1 \%$ crude sunflower oil, the samples were placed for stirring in a paddle stirrer for 30 minutes. Then to each sample slowly, with stirring, was introduced $3 \%$ crude sunflower oil, stirred for 25 minutes after the end of the introduction at high speed $1500 \mathrm{rpm}$. Subsequently calculating the parameters of the samples with $3 \%$ crude sunflower oil, the samples were placed for stirring in a paddle stirrer for 30 minutes. Then to each sample slowly, with stirring, was introduced $5 \%$ crude sunflower oil, stirred for 25 minutes after the end of the introduction at high speed $1500 \mathrm{rpm}$. The results are shown in Table 3.
Similar studies and measurements were performed for castor oil. After measuring the parameters of the pure solution, the samples were placed for stirring in a paddle stirrer for 30 minutes. Then to each sample slowly, with stirring, was introduced $0.5 \%$ castor oil, stirred for 25 minutes after the end of the introduction at high speed $1500 \mathrm{rpm}$. The previous determined the physicochemical properties of castor oil. The obtained data are shown in Table 2 .

After measuring the parameters of the samples with $0.5 \%$ castor oil, the samples were placed for stirring in a paddle stirrer for 30 minutes. Then to each sample slowly, with stirring, was introduced $1 \%, 3 \%$ and $5 \%$ castor oil, stirred for 25 minutes after the end of the introduction at high speed of $1500 \mathrm{rpm}$. The data obtained are summarized in Table 4.

Physicochemical characteristics of the investigated solutions

\begin{tabular}{|c|c|c|c|c|c|c|c|c|c|c|c|c|c|}
\hline \multirow{2}{*}{ Drilling fluid } & \multirow{2}{*}{$\begin{array}{c}\rho, \\
\mathrm{kg} / \mathrm{m}^{3}\end{array}$} & \multirow{2}{*}{$V, \mathrm{~s}$} & \multirow{2}{*}{$\mathrm{pH}$} & \multirow{2}{*}{\begin{tabular}{|c|}
$\begin{array}{c}F^{*}, \mathrm{~cm}^{3} / 30 \mathrm{~min} \\
\text { at } 20{ }^{\circ} \mathrm{C}\end{array}$ \\
$\mathrm{F} 7.5 / \mathrm{F} 30$ \\
\end{tabular}} & \multirow{2}{*}{$\begin{array}{c}\text { Filter cake } \\
\text { thickness, } \\
\text { mm }\end{array}$} & \multirow{2}{*}{ CFC } & \multicolumn{2}{|c|}{ M-800 } & \multirow{2}{*}{$\begin{array}{l}A V_{,} \\
\mathrm{CP}\end{array}$} & \multirow{2}{*}{$\begin{array}{l}P V, \\
\mathrm{cP}\end{array}$} & \multirow{2}{*}{$\begin{array}{l}Y P_{\prime}^{\prime} \\
\mathrm{ft}^{2}\end{array}$} & \multicolumn{2}{|c|}{ GEL } \\
\hline & & & & & & & 600 & 300 & & & & $10 \mathrm{~s}$ & $10 \mathrm{~m}$ \\
\hline WBM & 1015 & 18 & 9.4 & 17 & 3 & 0.061 & 14.7 & 10.0 & 8 & 5.3 & 23 & 8.6 & 24 \\
\hline WBM+10 \% KCl+1 \% CMC & 1100 & 31 & 9.0 & 17.5 & 4 & 0.123 & 46.0 & 24.0 & 23 & 21 & 14.4 & 0.96 & 5.3 \\
\hline WBM+10 \% KCl+15 \% NaCl+1 \% CMC & 1120 & 19 & 8.2 & 7.0 & 0.5 & 0.105 & 17.4 & 9.4 & 9 & 8.1 & 6.2 & 0 & 0 \\
\hline
\end{tabular}

Note: $F^{*}-$ if the filtration is more than $40 \mathrm{~cm}^{3}$ (filter press settles immediately). Then write the mark «n». Otherwise measure in 7.5 minutes

Physicochemical characteristics of the studied oils

\begin{tabular}{|c|l|c|c|}
\hline $\begin{array}{c}\text { No. } \\
\text { items }\end{array}$ & \multicolumn{1}{|c|}{ Indicator name } & Haw sunflower oil & Castor oil \\
\hline 1 & Exterior & $\begin{array}{l}\text { Homogeneous oily yellow liquid, transparent without curtain } \\
\text { and sediment with a characteristic odor, very slow drying }\end{array}$ & $\begin{array}{c}\text { Homogeneous oily liquid of yellow colour, transparent } \\
\text { without a curtain and a deposit, very slowly drying }\end{array}$ \\
\hline 2 & Dry residue, mas., \% & 99.91 & 99.95 \\
\hline 3 & Density, $\mathrm{kg} / \mathrm{m}^{3}$ & 930 & 950 \\
\hline 4 & Conditional viscosity, $\mathrm{s}$ & 72 & Very viscous \\
\hline 5 & Hydrogen index, $\mathrm{pH}$ & - & 5 \\
\hline 6 & Solubility in water & Insoluble. Floats to the surface & Insoluble \\
\hline 7 & Solubility in kerosene & Dissolves to form an unstable foam. Slight precipitation & Dissolves \\
\hline 8 & Laefficient of lubricating properties & 0.09 & - \\
\hline
\end{tabular}

Parameters of drilling fluids with the addition of sunflower oil

\begin{tabular}{|c|c|c|c|c|c|c|c|c|c|c|c|c|c|}
\hline \multirow{2}{*}{$\%$ oil content } & \multirow{2}{*}{$\rho, \mathrm{kg} / \mathrm{m}^{3}$} & \multirow{2}{*}{$V, \mathrm{~s}$} & \multirow{2}{*}{$\mathrm{pH}$} & \multirow{2}{*}{\begin{tabular}{|c|}
$F^{*}, \mathrm{~cm}^{3} / 30 \mathrm{~min}$ at $20{ }^{\circ} \mathrm{C}$ \\
$\mathrm{F} 7.5 / \mathrm{F} 30$ \\
\end{tabular}} & \multirow{2}{*}{$\begin{array}{c}\text { Filter cake } \\
\text { thickness, } \\
\text { mm }\end{array}$} & \multirow{2}{*}{$C F \Gamma$} & \multicolumn{2}{|c|}{ M-800 } & \multirow{2}{*}{$A V, \mathrm{cP}$} & \multirow{2}{*}{$P V, \mathrm{cP}$} & \multirow{2}{*}{$Y P, \mathrm{ft}^{2}$} & \multicolumn{2}{|c|}{$G E L$} \\
\hline & & & & & & & 600 & 300 & & & & $10 \mathrm{~s}$ & $10 \mathrm{~m}$ \\
\hline \multicolumn{14}{|c|}{ WBM } \\
\hline $0.5 \%$ sunflower oil & 1020 & 18 & 9.1 & 17 & 0.5 & 0.04 & 19.6 & 14 & 10 & 5.8 & 40 & 13 & 20 \\
\hline $1 \%$ sunflower ail & 1020 & 18 & 9.3 & 15.8 & 1.0 & 0.06 & 14.9 & 10.5 & 7.45 & 4.4 & 29.3 & 13.4 & 20.6 \\
\hline $3 \%$ sunflower ail & 1015 & 19 & 9.0 & 19.5 & 1.0 & 0.08 & 17.7 & 12.4 & 9.0 & 5.3 & 34.6 & 11 & 16.3 \\
\hline $5 \%$ sunflower ail & 1015 & 19 & 9.0 & 20.5 & 0.5 & 0.08 & 16 & 10.9 & 8.0 & 5.1 & 28.3 & 11.0 & 15.4 \\
\hline \multicolumn{14}{|c|}{ WBM+10 \% KCI+1 \% СМГ } \\
\hline 0.5 \% sunflower oil & 1140 & 31 & 8.9 & 19 & 3.0 & 0.09 & 40.2 & 21 & 20 & 19.2 & 9.0 & 3.0 & 7.0 \\
\hline $1 \%$ sunflower oil & 1135 & 25 & 8.9 & 19.2 & 1.0 & 0.14 & 30.5 & 15.7 & 15 & 14.8 & 5.0 & 2.0 & 7.7 \\
\hline $3 \%$ sunflower ail & 1135 & 24 & 8.8 & 18.8 & 1.0 & 0.10 & 33.1 & 17 & 17 & 16.1 & 3.84 & 2.4 & 8.2 \\
\hline $5 \%$ sunflower ail & 1125 & 24 & 8.8 & 20.8 & 1.0 & 0.09 & 26.8 & 13.1 & 13.4 & 13.3 & 0.2 & 0.1 & 0.5 \\
\hline \multicolumn{14}{|c|}{ WBM+10 \% KCl+15\% NaCl+1 \% CMC } \\
\hline $0.5 \%$ sunflower oil & 1170 & 19 & 8.1 & 7.5 & 0.5 & 0.09 & 17 & 11 & 9.0 & 5.7 & 27 & 11 & 18 \\
\hline $1 \%$ sunflower oil & 1170 & 20 & 8.1 & 7.0 & 0.5 & 0.07 & 16.3 & 8.5 & 8.1 & 7.8 & 3.4 & 0.5 & 0.5 \\
\hline $3 \%$ sunflower oil & 1165 & 21 & 8.0 & 6.8 & 0.5 & 0.08 & 17.2 & 8.6 & 8.1 & 7.5 & 5.3 & 0.6 & 0.6 \\
\hline 5 \% sunflower ail & 1165 & 19 & 8.0 & 6.8 & 0.5 & 0.04 & 16.8 & 9.1 & 8.4 & 7.7 & 6.72 & 0.96 & 0.96 \\
\hline
\end{tabular}

Note: $F^{*}$ - if the filtration is more than $40 \mathrm{~cm}^{3}$ (filter press settles immediately), then write the mark «n», atherwise measure in 7.5 minutes 
Parameters of drilling fluids with the addition of castor oil

\begin{tabular}{|c|c|c|c|c|c|c|c|c|c|c|c|c|c|}
\hline \multirow{2}{*}{$\%$ oil content } & \multirow{2}{*}{$\rho, \mathrm{kg} / \mathrm{m}^{3}$} & \multirow{2}{*}{$V, \mathrm{~s}$} & \multirow{2}{*}{$\mathrm{pH}$} & \multirow{2}{*}{\begin{tabular}{|c|}
$F^{*}, \mathrm{~cm}^{3} / 30 \mathrm{~min}$ at $20{ }^{\circ} \mathrm{C}$ \\
$\mathrm{F} 7.5 / \mathrm{F} 30$
\end{tabular}} & \multirow{2}{*}{$\begin{array}{c}\text { Filter cake } \\
\text { thickness, } \\
\text { mm }\end{array}$} & \multirow{2}{*}{$C F[$} & \multicolumn{2}{|c|}{ M-800 } & \multirow{2}{*}{$A V, \mathrm{cP}$} & \multirow{2}{*}{$P V, \mathrm{cP}$} & \multirow{2}{*}{$Y P, \mathrm{ft}^{2}$} & \multicolumn{2}{|c|}{ GEL } \\
\hline & & & & & & & 600 & 300 & & & & $10 \mathrm{~s}$ & $10 \mathrm{~m}$ \\
\hline \multicolumn{14}{|c|}{ WBM } \\
\hline $0.5 \%$ castar oil & 1020 & 23 & 9.3 & 16 & 1.5 & 0.06 & 22 & 15.9 & 11 & 6.7 & 44 & 17.3 & 19.7 \\
\hline $1 \%$ castor oil & 1020 & 24 & 9.3 & 16 & 1.0 & 0.03 & 22.6 & 14.5 & 12 & 6.7 & 47 & 18 & 28 \\
\hline $3 \%$ castor oil & 1090 & 22 & 9.2 & 14.8 & 0.5 & 0.07 & 28.7 & 20.2 & 14.9 & 8.3 & 61 & 19 & 21 \\
\hline $5 \%$ castor oil & 1120 & 23 & 9.07 & 14 & 0.5 & 0.07 & 26.7 & 18.6 & 13.4 & 8.3 & 53 & 23 & 28 \\
\hline \multicolumn{14}{|c|}{ WBM+10 \% KC]+1 \% СМГ } \\
\hline $0.5 \%$ castor oil & 1095 & 25 & 8.9 & 13 & 0.5 & 0.08 & 33 & 18.4 & 16.5 & 14.7 & 18 & 4.8 & 8.64 \\
\hline $1 \%$ castor oil & 1095 & 22 & 8.9 & 14.5 & 1.0 & 0.096 & 30 & 16.8 & 15 & 13.2 & 17.3 & 3.8 & 6.7 \\
\hline $3 \%$ castor oil & 1090 & 23 & 8.85 & 14 & 0.5 & 0.14 & 30.4 & 16.9 & 15.2 & 13.5 & 18 & 2.0 & 6.0 \\
\hline $5 \%$ castor oil & 1090 & 23 & 8.76 & 14.4 & 0.5 & 0.11 & 26.5 & 14.7 & 13.3 & 11.9 & 14 & 1.0 & 5.0 \\
\hline \multicolumn{14}{|c|}{ WBM+10 \% KCl+15 \% NaCl+1 \% CMC } \\
\hline $0.5 \%$ castar oil & 1170 & 20 & 8.2 & 7.0 & 0.5 & 0.048 & 17 & 9.2 & 8.5 & 7.7 & 7.2 & 0.96 & 1.44 \\
\hline $1 \%$ castor oil & 1170 & 20 & 8.2 & 7.5 & 0.5 & 0.087 & 17.7 & 9.7 & 8.9 & 8.1 & 7.7 & 2.9 & 2.4 \\
\hline $3 \%$ castor oil & 1116 & 20 & 8.2 & 7.0 & 0.5 & 0.08 & 19 & 10.4 & 9.5 & 8.6 & 9.00 & 1.0 & 1.0 \\
\hline $5 \%$ castor oil & 1120 & 21 & 8.1 & 7.0 & 0.5 & 0.09 & 21 & 11 & 10.5 & 9.2 & 9.2 & 1.2 & 1.2 \\
\hline
\end{tabular}

Note: $F^{*}$ - if the filtration is more than $40 \mathrm{~cm}^{3}$ (filter press settles immediately), then write the mark "n», atherwise measure in 7.5 minutes

\section{Research results and discussion}

The effect of lubricating additives of crude sunflower and castor oils on lubricating and rheological characteristics of drilling fluids was investigated. After measuring the parameters of the solution samples with the addition of a certain percentage of crude sunflower and castor oils according to standard API methods, the obtained data were summarized in Tables 3 and 4 .

The study of the effect of sunflower oil on the main characteristics of drilling fluids showed the following. While a certain concentration of sunflower oil is added to a fresh solution, we observe visible signs of oil, it floats somewhat on the surface, and the solution hardly foams and is less greasy to the touch. After a certain concentration of sunflower oil is added to a mineralized solution, the oil almost does not float on the surface of the solution, dissolves in salt, the solution does not foam and is less greasy to the touch. When a certain concentration of oil is added to a salty solution, the oil floats somewhat on the surface of the solution (less than in fresh, but more than in saline), the solution does not foam and is greasy to the touch. As for other characteristics, as the concentration of sunflower oil in the test solutions increases, the density, conditional viscosity (slightly changes in a saline solution), and $\mathrm{pH}$ do not change almost.

Static shear stress, filtration value, filtration crust thickness (except for solution $\mathrm{WBM}+0 \% \mathrm{KCl}+15 \% \mathrm{NaCl}+$ $+1 \%$ CMC, where the CFC value remains unchanged), and rheological properties change significantly. The CFC for the studied WBM solution is reduced by adding $0.5 \%$ sunflower oil, which 1.5 times improves the lubricating properties of this solution. For a solution of WBM type $+10 \% \mathrm{KCl}+$ $+1 \%$ CMC CFC decreases with the addition of $0.5 \%$, $3 \%$, and $5 \%$ sunflower oil, which improves the lubricating properties of this solution by 1.4, 1.2, and 1.4 times, respectively. CFC for the studied saline solution (WBM+ $+10 \% \mathrm{KCl}+15 \% \mathrm{NaCl}+1 \% \mathrm{CMC}$ ) decreases with the addition of all \% concentrations of oil, but most with the addition of $5 \%$ oil, which 1.5 times improves the lubricating properties of this solution. Thus, sunflower oil effectively affects the saline solution and improves its lubricating characteristics.

The obtained dependences of the established percentage of lubricating additives of sunflower oil on the coefficient of lubricity of the solution in the system «metal - metal» (coefficient of friction of the crust), which characterize the lubricating qualities of the solutions, are presented in Fig. 1.

The obtained dependences of the established percentage of lubricating additives of sunflower oil on the amount of filtration of solutions are presented in Fig. 2.

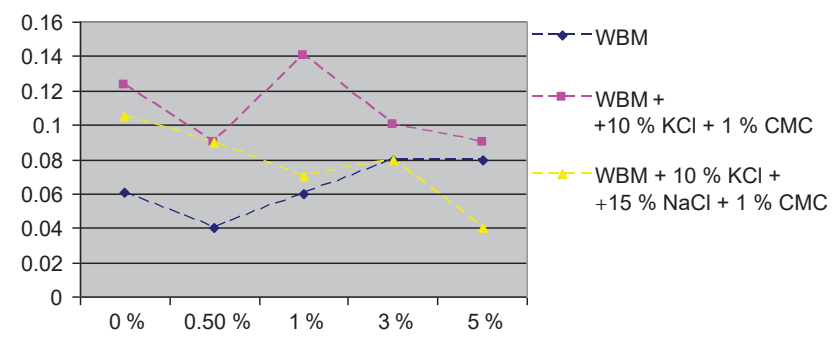

Fig. 1. Influence of $\%$ - concentration of sunflower oil on the coefficient of friction of the crust (CFC) of the studied types of drilling fluids

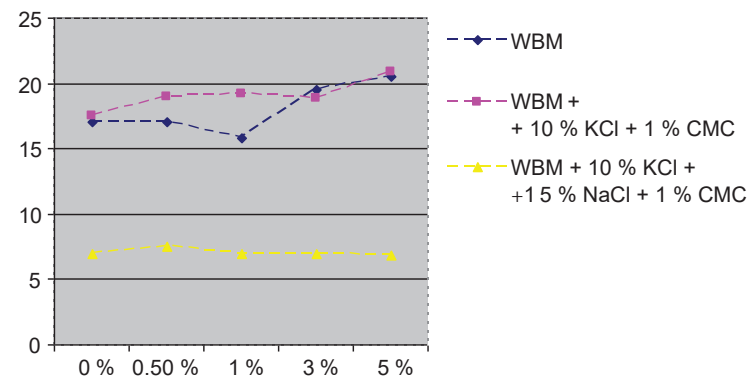

Fig. 2. Influence of $\%$ - concentration of sunflower oil on the value of filtration of the studied types of drilling fluids

The study of the influence of castor oil on the main characteristics of drilling fluids showed the following. 
When a certain concentration of castor oil is added to a fresh solution, we observe very thin visible signs of oil, the structure of the solution has not changed, and the solution remains homogeneous. After a certain concentration of castor oil is added to a saline solution, the oil on the surface of the solution forms a film and dissolves slightly in the solution. While a certain concentration of oil is added to a saline solution, the oil partially floats to the surface of the solution. As the concentration of castor oil in the test solutions increases, their main characteristics change significantly. According to the CFC for the studied fresh solution, the friction coefficient remains almost unchanged. The value of the coefficient decreases significantly for oil concentrations of $1 \%$, which improves the lubricating properties of the solution by 2.03 times.

For a solution of WBM type $+10 \% \mathrm{KCl}+1 \% \mathrm{CMC} \mathrm{CFC}$ decreases with the addition of $0.5 \%, 1 \%$, and $5 \%$ castor oil, which improves the lubricating properties of this solution, respectively, by 1.54, 1.3, and 1.12 times. CFC for the saline solution of $\mathrm{WBM}+10 \% \mathrm{KCl}+15 \% \mathrm{NaCl}+1 \% \mathrm{CMC}$ decreases with the addition of all concentrations of castor oil, which indicates the possibility of giving this solution better lubricating characteristics than fresh and mineralized solutions.

The obtained dependences of the established percentage of lubricating additives of castor oil on the coefficient of lubricity of the solution in the system «metal - metal» (coefficient of friction of the clay crust), which characterize the lubricating qualities of solutions, are presented in Fig. 3.

The obtained dependences of the set percentage of lubricating additives of castor oil on the amount of filtration of solutions are presented in Fig. 4.

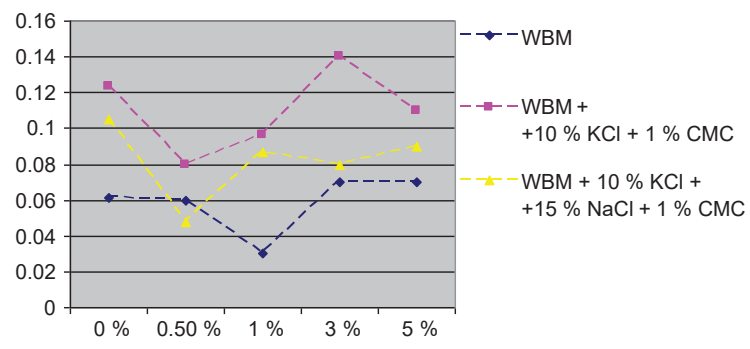

Fig. 3. Influence of $\%$ - concentration of castor oil on the coefficient of friction of the crust (CFC) of the studied types of drilling fluids

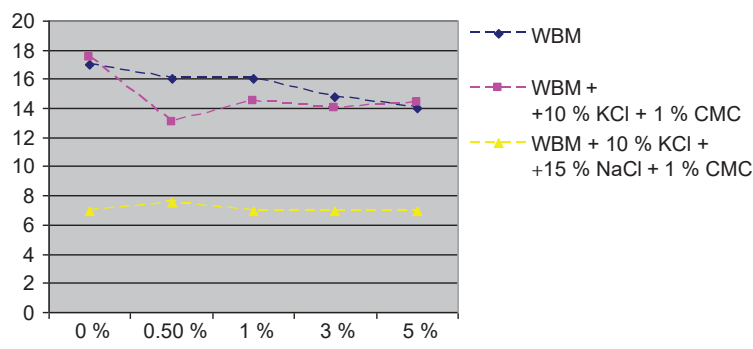

Fig. 4. Influence of \% - concentration of castor oil on the amount of filtration of the studied types of drilling fluids

Studies have established fairly high tribological properties of vegetable oils - rapid interaction with metals, high lubricity, corrosion protection, neutral attitude to the seals [2].

The use of vegetable oils as a basis for lubricating and cooling technological environments (MOTS) is receiving increasing attention in the works of researchers [7].

Lubricants based on products of plant and animal origin have been widely used in engineering since the Bronze
Age to the middle of the XX century - ghee and pork fat (oil for the axles of the wheels of railway cars), olive oil (motor oils), whale oil (industrial oils for textile equipment, transmission oils), castor oil (technological oil for metalworking), coconut (oil for rolling metals), tall oil (a component of cylinder oils) [8].

The most promising in terms of widespread use in engineering are rapeseed and sunflower oils [2]

In world practice, the development of technological fluids using castor and rapeseed oil is known. Thus, the company «Baroid» (USA) in co-authorship with the company «Henkel KGap» (Germany) practiced the use of liquid systems called «Petrofee», similar systems are offered by the company «British Petroleum Development» (UK), certain elements of novelty from the experience of castor oil was introduced by OJSC «Drilling» (RF) [6].

Numerous studies show that the addition of castor oil effectively reduces the friction coefficient of the filtration crust, formed from both artificial and natural drilling fluids, and does not adversely affect the basic properties of the solution. The recommended addition of this reagent to the drilling fluid is $0.3-0.5 \%$ [9].

It is known, that in many countries work is underway to obtain lubricating plastic lubricating additives on the basis of vegetable oils, most intensively - in the United States, Great Britain, Germany, Austria. In the works of scientists the properties of modified vegetable oils and the possibility of using them as lubricants are considered. In many cases, the most important aspect that makes vegetable oils attractive as a component of lubricant is their high content of oleic acid [10].

Also, the main advantage of vegetable oil is its environmental friendliness. Thus, after exposure to the environment, oils are relatively quickly subjected to complete decomposition. Vegetable oils are a renewable resource that can be used as reliable source material for new products with a wide range of structural and functional variations. Wide availability and relatively low cost make vegetable oils an attractive raw material for industry. For a long time, vegetable oils and their derivatives are used by chemists because of their novelty, availability around the world at a relatively low price, and their widespread use [11].

Consequently, when making a decision on the creation and implementation of new technology, not only its advantages over the analog in terms of technical and technological parameters are taken into account, but also the possible economic and environmental results of its application in production are taken into account.

Nowadays, in the course of lubricating additives testing specialists pay attention to:

- a shear rate of the filter cake. It is the value that characterizes the strength of filter cake and is determined by the ratio of strength, necessary for the tangential displacement of cyclic load across the cake to its weight;

- friction coefficient of the filter cake. It is the value

that indirectly characterizes the lubricating properties of drilling fluid [12].

The friction coefficient is the main criterion for evaluation of lubricating properties of additives and its decrease is a characteristic of their effectiveness. Due to the fact that along with the necessary highly effective lubricating additives the less effective agents are sometimes being tested, the use of the latter being, able to deteriorate the technical and cost performance of drilling, the drilling fluid 
performance, and cost overrun, the said testing shall be carried out using several professional instruments, such as KTK, КТК-2, Sticking Tester OFI (USA). The latter is used in accordance with API standard to measure friction coefficient when the $\mathrm{v}$-block is pressed to the ring at the load of $1.03 \mathrm{MPa}$ (150 pounds per square inch) and shaft rotation frequency of $60 \mathrm{~min}^{-1}$ (Fig. 3) [13].

As a result, taking into account the above, in the future it is planned to repeat the study on the Sticking Tester OFI (USA) and use lubricants of other natural oils.

\section{Conclusions}

As a result of research, the main properties and parameters of water-clay drilling fluids (fresh, mineralized and saline) were analyzed using standard API techniques, which made it possible to determine for which type of solution the addition of sunflower and castor oil lubricants is more favorable.

Based on the above studies, it can be concluded, that the addition of castor oil effectively reduces the coefficient of friction of the filtration crust, formed from the studied drilling fluids (fresh, mineralized, and saline). The recommended concentrations of this oil to the drilling fluid are $0.5 \%, 1 \%$, and $5 \%$. Sunflower oil has an effective influence on the saline solution, less effective - on the mineralized with an oil concentration of $0.5 \%, 3 \%$, and $5 \%$.

\section{References}

1. Zakirov, A. (2011). Secondary use of waste from the forest chemical industry in drilling fluids. Scientific works: DonNTU. Mining and Geological Series, 14 (181), 238-240. Available at: http://ea.donntu. org:8080/jspui/bitstream/123456789/15301/1/238-240.pdf

2. Bakulin, E., Draganchuk, O., Protsyshyn, V. (2011). Lubricating additives and their influence on the functional properties of drilling fluids. Exploration and development of oil and gas fields, 4 (41), 101-106. Available at: http://elar.nung.edu.ua/ bitstream/123456789/3773/1/2878p.pdf

3. Kusturova, O., Shevchenko, R., Zhugan, O., Lyamenkov, S. (2013). Lubricating impurities in drilling and methods of their research. Oil and gas industry of Ukraine, 4, 7-9. Available at: http://www.naftogaz.com/files/journal/4_2013_preview.pdf
4. Litvinets, A. (2005). Investigation of new lubricating impurities to increase the anti-stick properties of washing liquids. Exploration and development of oil and gas fields, 4 (17), 89-91. Available at: http://194.44.112.13/journals/234p.pdf

5. Magun, M. Ya., Gursky, S. A., Zinkov, R. V. (2015). Optimization of lubricating impurity of lignosulfonate-potassium drilling fluid. Oil and gas industry of Ukraine, 1, 7-13. Available at: http://www.naftogaz.com/files/journal/1_2015_preview.pdf

6. Filippov, E. F., Nifontov, Yu. A., Nikolaev, N. I., Sharafutdinov, Z. Z. (2004). Management of rheological properties of drilling rastovorov. Coll. scientific. Tr.: JSC NPO Burenie, 12, 83-95.

7. Aliev, A. I. (2012). Temperature changes of tribological properties of castor oil. Bulletin of NTUU «KPI», 44, 122-127. Available at: https://ela.kpi.ua/bitstream/123456789/3443/1/r_7_2.pdf

8. Chudnovskaja, A. V., Hasanov, R. M., Valiev, R. R. (2016). Environmentally sound application of invert emulsion drilling mud based on vegetable oil. Oil and Gas Business, 6, 70-80. doi: http://doi.org/10.17122/ogbus-2016-6-70-80

9. Petrov, N. A., Davydov, I. N. (2013). Study of specially prepared vegetable based fluid and additive combinations used as drilling mud lubricants. Oil and Gas Business: Geology, Geophysics, Drilling, 4, 42-58. Available at: http://ngdelo.ru/files/ old_ngdelo/2013/4/2013-t11-4.pdf

10. Prysiajna, K. O. (2017). Ecologically safe mastic materials for recycling technologies for polydimensional inputs. Khmelnytskyi, 168 Available at: http://lutsk-ntu.com.ua/sites/default/files/dis_4.pdf

11. Protopopov, A. V., Shleina, A. N., Kuris, Iu. E., Bobrovskaia, S. A., Shumilova, E. Iu. (2017). Thermal modification of vegetable oils in the presence of sulfur. Polzunovsky Vestnik, 4, 21-25. Available at: http://elib.altstu.ru/journals/Files/pv2017 04/ pdf/021 Protopopov.pdf

12. Control of parameters of drilling fluids: SOU 11.2-00135390-096:2009 (2009). Kyiv: PJSC «Ukrnafta», 100.

13. Mahun, M. Ya., Hurskyi, S. A., Zinkov, R. V., Versta, O. M., Stefanyk, V. (2015). Optimization of potassium lignosulfonate drilling fluid lubricating additive. Oil and gas industry of Ukraine, 1, 7-13. Available at: https://www.naftogaz.com/ files/journal/1_2015_preview.pdf

Viktoriia Dmytrenko, PhD, Associate Professor, Department of «Oil and Gas Engineering and Technology», National University «Yuri Kondratyuk Poltava Polytechnic», Poltava, Ukraine, ORCID: https:// orcid.org/0000-0002-1678-2575,e-mail:dmytr.v@gmail.com

Yuliia Diachenko, Lecturer, Commission of Operational Disciplines, Poltava Oil and Gas College of National University «Yuri Kondratyuk Poltava Polytechnic», Poltava, Ukraine, ORCID: https:// orcid.org/0000-0001-7068-4725,e-mail: dzuliya@ukr.net 